\title{
R\&D investment decision and optimal subsidy
}

\section{Jyh-bang Jou ${ }^{1}$ and Tan Lee ${ }^{2}$}

\author{
${ }^{1}$ National Taiwan University, College of Social Science, No. 1 Roosevelt Rd., Sec. 4, Taipei 106, Taiwan, ROC \\ jbjou@ccms.ntu.edu.tw \\ ${ }^{2}$ Takming College
}

\begin{abstract}
This article assumes that a firm facing technological uncertainty must decide whether to purchase R\&D capital at each instant. R\&D capital exhibits both irreversibility and externality through the learning-bydoing effect. The combination of irreversibility and uncertainty drives agents to be more prudent; the maxim 'better safe than sorry' applies. This maxim is more important if uncertainty is greater, technology progresses at a lower pace, the externality is stronger, or a catastrophic event is less likely to occur. A firm ignoring the externality will both invest later and disinvest earlier than a social planner who internalizes the externality. An equal rate of investment tax credits should be given to both costlessly reversible investments and irreversible ones, and the same rate of taxation should be imposed on disinvestment.
\end{abstract}

\section{Introduction}

$\mathbf{R}$ esearch and Development (R\&D) activities have three major characteristics. First, R\&D outlays are usually irreversible. Second, the future rewards from R\&D activities are usually uncertain. Finally, R\&D activities may exhibit positive externalities. Previous literature fails to combine these characteristics. The literature on the 'endogenous growth' theory (see Romer, 1986) emphasizes the last one while abstracting from the first two. In contrast, real options literature (see Dixit and Pindyck, 1994; Schwartz and Moon, 2000) emphasizes the first two while ignoring the last one. This article will introduce externalities into real options literature so as to examine the issues regarding both $R \& D$ investment decisions and the optimal R\&D subsidy.

We assume the industry considered has a fixed number of identical firms and its demand function has constant elasticity. Each firm's production is in a Cobb-Douglas form with respect to its employed workers, its employed R\&D capital, the industry's average amount of R\&D capital, and a multiplicative technology-shift factor. The last one, which evolves as a mix of a Poisson process and a geometric Brownian motion, captures the uncertainty faced by all firms in the industry. The combination of irreversibility and uncertainty induces agents to be more prudent. Given that firms may either invest or disinvest $R \& D$ capital when the payoff is uncertain, this implies that agents will both invest later and disinvest earlier, compared to the case either when there is no uncertainty or when there is complete reversibility.

Externalities due to investments may result in inefficient market solutions, because a firm ignoring the externality will both invest later and disinvest earlier than a social planner. Accordingly, there is room for governmental intervention. This article will focus on both tax credits on investment and taxation on disinvestment while abstracting from any other policy instrument. This article will show that an equal rate of investment tax credits should be given to both costlessly reversible investments and irreversible ones. In addition, this optimal rate coincides with the optimal rate of taxation on disinvestment.

Before proceeding, it is important to place our analysis in the context of both real options and optimal subsidy literature. This article abstracts from two main 
aspects of $R \& D$ investment that have received attention in real options literature: ${ }^{1}$ sequential nature and strategic interactions between firms. On the one hand, Roberts and Weitzman (1981) suggest that the investment in R\&D is usually an 'exploratory' one that discloses information for the later-stage investment such as marketing or commercialization. Several articles on real options have incorporated this suggestion, see Bar-Ilan and Strange (1998), Dixit and Pindyck (1994, chapter 10), Grenadier and Weiss (1997), Lambrecht (2000), Pindyck (1993), and Schwartz and Moon (2000). In contrast, this article, like Weeds (1999a), assumes that $R \& D$ capital is input for producing final goods. On the other hand, Beath, Katsonlacos and Ulph (1989), Fudenberg et al. (1983), and Harris and Vickers (1985) have allowed firms to compete for R\&D investment. This has been incorporated into real options literature by Dixit and Pindyck (1994, chapter 9), Lambrecht (2000), and Weeds (1999b). In contrast, this article assumes that competition between firms is of a Cournot-Nash type, thus abstracting from the Stackelberg-type competition addressed by those articles.

Several articles examine the issue of optimal subsidy on capital while assuming that capital exhibits costless reversibility, e.g. Romer (1986) and Judd (1997). Romer considers that human capital rather than physical capital exhibits externalities through the 'learning-bydoing' effect. He finds that the optimal tax credit on human capital depends on the relative magnitude between the external and the internal effect of capital if the production technology is in a Cobb-Douglas form with respect to an individual firm's human capital input and the industry's aggregate stock of human capital. ${ }^{2}$ His results are similar to ours. Judd considers imperfect rather than perfect competitive markets. He shows that subsidies on capital should be higher if the gap between price and marginal cost is higher. His analysis thus justifies the investment tax credit policy commonly employed in the USA which favours equipment over structures. In contrast, this article abstracts from imperfect competitive markets and finds that investment tax credits should be equal across industries.

Section two develops the model for optimal individual and then social profit with respect to R\&D investment. Section three derives the optimal individual and social investments, along with the optimal tax and tax credits. Section four provides numerical examples, and section five concludes.

\section{The model}

Dixit (1991) builds a model to examine the impact of price ceilings on irreversible investment decisions. This article introduces externalities into his model while abstracting from price ceilings. The industry under consideration is composed of $N$ identical risk-neutral firms, indexed by 1 to $N$, which face a demand function with a constant-elasticity $\varepsilon(\geqslant 0)$, i.e.

$$
Q(t)=P(t)^{-\varepsilon},
$$

where $Q(t)$ is quantity, and $P(t)$ is price. The output of each firm $i$ depends on its employed labor force, denoted by $l_{i}(t)$, its employed capital stock, denoted by $k_{i}(t)$, the industry's average level of capital stock, denoted by $k_{a}(t)=\left(\sum_{j=1}^{N} k_{j}(t) / N\right)$, and a technologyshift factor, denoted by $Z(t)$. More precisely, the production technology is given by

$$
q_{i}(t)=l_{i}(t)^{\gamma}\left(Z(t) k_{i}(t)\right)^{1-\gamma} k_{a}(t)^{\lambda} .
$$

Two sources of technology uncertainty are considered. First, following Schwartz and Moon (2000) and Weeds (1999a), a catastrophic event that suddenly drives $Z(t)$ equal to zero is assumed to follow a Poisson process with a hazard rate $\mu$ (which is the probability per unit of time that drives $Z(t)$ to zero). Second, in the case where a catastrophic event does not happen, $Z(t)$ evolves as a geometric Brownian motion

$$
\mathrm{d} Z(t)=\eta Z(t) \mathrm{d} t+\sigma Z(t) \mathrm{d} \Omega(t),
$$

where the drift parameter $\eta$ is the expected growth rate of $Z(t)$ and the parameter $\sigma(>0)$ is the instantaneous volatility of the growth rate of $Z(t)$, and $\mathrm{d} \Omega(t)$ is an increment to a standard Wiener process, with $E\{\mathrm{~d} \Omega(t)\}=0$ and $E\{\mathrm{~d} \Omega(t)\}^{2}=\mathrm{d} t$. For high-technology environment such as DRAM production, $Z(t)$ may exhibit a higher expected growth rate. Accordingly, the expected unit production cost tends to decline over time. High-technology environment may also have a higher volatility of $Z(t)$, and therefore, may have a wide variation of unit production cost. Furthermore, the specification in (3) also indicates that information about the evolution of each individual firm's output that arrives in time is independent of its decision to invest. This contrasts with that of both Pindyck (1993) and Schwartz and Moon (2000) where uncertainty can be reduced over time through learning.

The production function given by (2) suggests that R\&D capital exhibits externality because the output of firm $i$ will be higher not only when the firm itself installs more capital, but also when any other firm in the industry installs more capital. This kind of externality may result from the 'leaning-by-doing' effect, which is first addressed by Arrow (1962) and is later widely employed by 'endogenous growth' models (e.g. Romer, 1986; Lucas, 1988). In (2), the effect of $k_{i}(t)$ on $q_{i}(t)$ is internal, and the term $1-\gamma$ measures its size. In contrast, the effect of $k_{a}(t)$ on $q_{i}(t)$ is external with $\lambda$ measuring its size.

Suppose that $q(t)=\left(q_{1}(t), \ldots, q_{N}(t)\right) \quad$ and $k(t)=\left(k_{1}(t), \ldots, k_{N}(t)\right)$. Denote $w$ as the wage rate. From (2), firm $i$ 's short-run variable cost, $w l_{i}(t)$, will then be given by

$$
C_{i}(q(t), k(t), Z(t))=w q_{i}(t)^{g}\left(Z(t) k_{i}(t)\right)^{1-g} k_{a}(t)^{-\lambda g},
$$


where $g=1 / \gamma>1$. Differentiating (4) with respect to $q_{i}(t)$ yields firm $i$ 's short-run marginal cost as given by

$M C_{i}(q(t), k(t), Z(t))=w g q_{i}(t)^{g-1}\left(Z(t) k_{i}(t)\right)^{1-g} k_{a}(t)^{-\lambda g}$.

The operating flow profit of firm $i$, denoted by $\pi_{i}(q(t), k(t), Z(t))$, is equal to its revenue, $P(t) q_{i}(t)$, net of its operating cost, $C_{i}(\cdot)$ in (4), thus yielding

$$
\pi_{i}(q(t), k(t), Z(t))=P(t) q_{i}(t)-C_{i}(q(t), k(t), Z(t)) .
$$

In (Cournot-Nash) short-run equilibrium, firm $i$ will take the other firms' production strategies as given while choosing an amount of output, denoted by $q_{i}(t)^{*}$, to maximize its operating flow profit, $\pi_{i}(\cdot)$ given by (6). Consequently, $q_{i}(t)^{*}$ is derived by setting the derivative of $\pi_{i}(\cdot)$ with respect to $q_{i}(t)$ equal to zero. This yields the equality of the marginal revenue, $1-q_{i}(t) /(\varepsilon Q(t))$ multiplied by $P(t)$ defined in (1), with the short-run marginal cost, $M C_{i}(\cdot)$ given by (5). This equality, together with the equilibrium condition $q_{i}(t)=q_{i}(t) *(j=1, \ldots, N)$ yields $q_{i}(t) *$ and its corresponding $P(t)^{*}$ as respectively given by

$$
\begin{aligned}
q_{i}(t) * & {\left[\frac{w}{\gamma} N^{e}\left(1-\frac{e}{N}\right)^{-1}\right]^{-1 /(e+g-1)} } \\
& \times\left[\left(Z(t) k_{i}(t)\right)^{1-\gamma} k_{a}(t)^{\lambda}\right]^{g /(e+g-1)},
\end{aligned}
$$

and

$$
\begin{aligned}
& P(t)^{*}=\left[\frac{w}{\gamma}\left(1-\frac{e}{N}\right)^{-1}\right]^{e /(e+g-1)} \\
& \times N^{-e(g-1) /(e+g-1)}\left[\left(Z(t) k_{i}(t)\right)^{1-\gamma} k_{a}(t)^{\lambda}\right]^{-e g /(e+g-1)},
\end{aligned}
$$

where $e=1 / \varepsilon$, which is required to be smaller than the number of firms $N$ to ensure that $q_{i}(t)^{*}$ and $P(t)^{*}$ are both positive.

Evaluating $\pi_{i}(\cdot)$ given by (6) at $q_{i}(t)=q_{i}^{*}(t)$ $(j=1, \ldots, N)$ yields the optimized value of firm $i$ 's private flow profit, denoted by $\pi_{i}^{1}(k(t), Z(t))$, as shown by (9) below. Define $f=e g /(e+g-1)$, then

$$
\pi_{i}^{1}(k(t), Z(t))=d_{0} Z(t)^{(1-f)} k_{i}(t)^{(1-f)} k_{a}(t)^{(1-e) f \lambda / e},
$$

where

$$
\begin{array}{r}
d_{0}=\left(1-\left(1-\frac{e}{N}\right) \gamma\right) N^{(-f)}\left(1-\frac{e}{N}\right)^{(1-e) /(e+g-1)} \\
\times\left(\frac{w}{\gamma}\right)^{(e-1) /(e+g-1)}
\end{array}
$$

In contrast, a social planner will internalize the external effect of R\&D capital before investing. The social planner understands that firm $i$ 's capital stock, $k_{i}(t)$, is equal to the industry's average level of capital stock, $k_{a}(t)$, because all firms are identical. Substituting this equality into the right-hand side of (9) yields the optimized value of the social flow profit, denoted by $\pi_{i}^{2}\left(k_{i}(t), Z(t)\right)$, as given by

$$
\pi_{i}^{2}\left(k_{i}(t), Z(t)\right)=d_{0} Z(t)^{(1-f)} k_{i}(t)^{(1-f+(1-e) f \lambda / e)} .
$$

\section{Optimum investment tax credits}

For ease of exposition, we ignore capital depreciation and assume that the purchasing and installation price of capital is constant over time, denoted by $P_{K}$. The resale price of capital is denoted by $\theta P_{K}$, where $1 \geqslant \theta \geqslant 0$. When $\theta=1$, then capital exhibits complete reversibility; otherwise, capital exhibits at least partial irreversibility. ${ }^{3}$

When R\&D capital exhibits externality, as suggested by (2), then market outcomes will be inefficient. The policy to correct this includes an investment tax credit, deposit-refund schemes, and accelerated depreciation (Hassett and Hubbard, 1996). In the following, we will focus on the first one. We assume there is a simplified tax system in which a government collects lump-sum taxes from firms, and then returns the proceeds to them in the form of an investment tax credit once they invest. The rate of this credit is denoted by $h$ so that the purchase price of capital faced by firms is given by $(1-h) P_{K}$. Similarly, we will assume that a government imposes a tax once firms disinvest and then returns the proceeds from taxation to them in the form of lumpsum transfers. The tax rate is denoted by $u$ so that the net revenue firms receive from selling per unit of capital is given by $(1-u) \theta P_{K}$.

\subsection{Costlessly reversible investment}

Suppose that investment is costlessly reversible, then $k_{i}(t)$ will be a choice variable rather than a state variable. Let $\rho$ denote a given discount rate. The $R \& D$ capital stock chosen by firm $i$ at each instant is found by equating the private marginal return to capital with the user cost of capital (Jorgenson, 1963), i.e.

$$
\frac{\partial \pi_{i}^{1}(k(t), Z(t))}{\partial k_{i}(t)}=(1-h)(\rho+\mu) P_{K} .
$$

The left-hand side of (11) indicates that the marginal return to firm $i$ 's capital is equal to the derivative with respect to $k_{i}(t)$ of its optimized private flow profit, $\pi_{i}^{1}(\cdot)$ given by (9). The right-hand side of (11) indicates that the user cost is equal to the rental cost of capital, $(1-h) \rho P_{K}$, plus capital loss, $(1-h) \mu P_{K}$; the latter arises because the probability of a catastrophic event can be interpreted as a 'tax rate' $\mu$ on the value of capital since on average a fraction of $\mu$ of this value 
will be lost per unit of time (Brennan and Schwartz, 1985). In (Cournot-Nash) industry equilibrium, each firm will choose an equal amount of capital stock, denoted by $K_{f 1}(\cdot, h, t)$, where the first subscript ' $f$ ' denotes the case for a frictionless world, and the second subscript ' 1 ' denotes the case for a decentralized economy. Substituting this equilibrium condition into (11), and then rearranging yields

$$
\begin{aligned}
& k_{f 1}(\cdot, h, t)=\left[\frac{d_{0}(1-e) f}{e(1-h)(\rho+\mu) P_{K}}\right. \\
& \left.\quad \times\left(1-\gamma+\frac{\lambda}{N}\right) Z(t)^{(1-f)}\right]^{1 /(f(1-(1-e) \lambda / e))} .
\end{aligned}
$$

To ensure that $k_{f 1}(\cdot, h, t)$ is decreasing with $P_{K}$, here and in what follows, we will assume that $e>(1-e) \lambda$. This inequality is more likely to hold if either demand elasticity is lower ( $\varepsilon$ is lower) or the external effect is less significant ( $\lambda$ is lower).

Similarly, the capital stock chosen by a social planner at each instant, denoted by $k_{f 2}(\cdot, t)$ (the second subscript ' 2 ' denotes the case for a centralized economy), is found by equating the social marginal return to capital, the derivative with respect to $k_{i}(t)$ of the optimized social flow profit, $\pi_{i}^{2}(\cdot)$ given by (10), with the user cost of capital, i.e. ${ }^{4}$

$$
\frac{\partial \pi_{i}^{2}\left(k_{i}(t), Z(t)\right)}{\partial k_{i}(t)}=(\rho+\mu) P_{K} .
$$

Evaluating the left-hand side of (13) at $k_{i}(t)=k_{f 2}(\cdot, t)$, and then rearranging yields

$$
\begin{aligned}
& k_{f 2}(\cdot, t)= \\
& {\left[\frac{d_{0}(1-e) f(1-\gamma+\lambda)}{e(\rho+\mu) P_{K}} Z(t)^{(1-f)}\right]^{1 /(f(1-(1-e) \lambda / e))} .}
\end{aligned}
$$

The role of externality is to raise the optimal stock of R\&D capital. In other words, in the absence of any investment tax credits $(h=0)$, the social marginal return to capital, the term on the left-hand side of (13), will outweigh the private marginal return to capital, the term on the left-hand side of (11). Consequently, the R\&D capital stock chosen by a social planner, $k_{f 2}(\cdot, t)$ given by (14), will be higher than that chosen by an individual firm, $k_{f 1}(\cdot, 0, t)$ given by (12). An investment tax credit can abolish this wedge, as suggested by Proposition 1 .

Proposition 1: Suppose that $h_{f}^{*}$ denotes the optimal rate of investment tax credits for $R \& D$ capital which exhibits complete reversibility, then

$$
h_{f}^{*}=\frac{\lambda}{(1-\gamma+\lambda)}\left(1-\frac{1}{N}\right) .
$$

Proof:

$h_{f}^{*}$ is the $h$ that satisfies the equality

$$
k_{f 1}(\cdot, h, t)=k_{f 2}(\cdot, t) .
$$

By replacing $k_{f 1}(\cdot, h, t)$ given by (12) with $k_{f 2}(\cdot, t)$ given by (14) yields $h_{f}^{*}$ as that shown by (15).

\subsection{Irreversible investment}

When R\&D capital exhibits irreversibility, then in the long-run, through Cournot-Nash competition, firm $i$ will maximize the expected discounted private flow profit, net of the costs from purchasing capital or plus the proceeds from selling capital, taking the strategies of the other firms as given (Baldursson, 1998; Dixit, 1991; Lucas and Prescott, 1971). Consequently, the Bellman value function of firm $i$, denoted by $V_{1}(k(t), Z(t))$, is given by

$$
\begin{aligned}
V_{1}(\cdot) & =\max _{\left\{k_{i}(\tau)\right\}} E_{t} \int_{t}^{\infty} e^{-\rho(\tau-t)}\left[\pi_{i}^{1}(k(\tau), Z(\tau)) \mathrm{d} \tau\right. \\
& \left.-1_{\left[\mathrm{d} k_{i}(\tau)>0\right]} P_{K} \mathrm{~d} k_{i}(\tau)+1_{\left[\mathrm{d} k_{i}(\tau)<0\right]} \theta P_{K} \mathrm{~d} k_{i}(\tau)\right],
\end{aligned}
$$

where $\pi_{i}^{1}(\cdot)$ is given by (9), $\rho$ is a given discount rate, $1_{[\cdot]}$ is an indicator function which is equal to one if the condition within [.] is satisfied, and zero otherwise, and $E_{t}\{\cdot\}$ denotes conditional expectation taken at time $t$. The maximization problem faced by firm $i$ amounts to choosing the optimal path for $k_{i}(t)$. There are $N+1$ state variables in this maximization problem, $k(t)$ and $Z(t) ; k_{-i}(t)=\left(k_{1}(t), \ldots, k_{i-1}(t), k_{i+1}(t), \ldots, k_{N}(t)\right)$ and $Z(t)$ are exogenously given, while $k_{i}(t)$ is subject to control. However, all $N-1$ elements of $k_{-i}(t)$ should be equal to $k_{i}(t)$ in industry equilibrium.

As is well known in real options literature (e.g. Dixit and Pindyck, 1994), the interaction of the stochastic evolution of $Z(t)$ and capital irreversibility indicates that firm $i$ solves a problem of two-side instantaneous control of Brownian motion; the optimal policy is to regulate the state variable $k_{i}(t)$ at both an upper barrier, denoted by $k_{i}(t)^{*}$, and a lower barrier, denoted by $k_{i}(t) *$ (Harrison and Taksar, 1985). In other words, as long as $k_{i}(t)^{*}>k_{i}(t)>k_{i}(t)_{*}$, no action will be taken (i.e. $\left.\mathrm{d} k_{i}(t)=0\right)$. However, when $k_{i}(t)$ hits $k_{i}(t)^{*}$, a minimum amount of capital to be sold is chosen to prevent $k_{i}(t)$ from rising above $k_{i}(t) *$ (i.e. $\left.\mathrm{d} k_{i}(t)<0\right)$. Similarly, when $k_{i}(t)$ hits $k_{i}(t) *$, a minimum amount of capital stock to be purchased is chosen to prevent $k_{i}(t)$ from falling below $k_{i}(t) *\left(\right.$ i.e. $\mathrm{d} k_{i}(t)>0$ ), the 'desired' capital stock coined by Bertola and Caballero (1994).

When $k_{i}(t)^{*}>k_{i}(t)>k_{i}(t)_{*}$, the private marginal gain from increasing the capital stock, $v_{i}(\cdot)=\partial V_{1}(\cdot) / \partial k_{i}(t)$, is given by (see Appendix A) 


$$
\begin{aligned}
v_{1}(\cdot)= & A_{1}\left[Z(t)^{(1-f)} k_{i}(t)^{(-f)} k_{a}(t)^{(1-e) f \lambda / e-1}\right. \\
& \left.\times\left(\theta k_{a}(t)+\frac{\lambda k_{i}(t)}{N}\right)\right]^{\beta} \\
& +\frac{d_{0}(1-e) f}{\phi(1) e} Z(t)^{(1-f)} k_{i}(t)^{(-f)} k_{a}(t)^{(1-e) f \lambda / e-1} \\
& \times\left(\theta k_{a}(t)+\frac{\lambda k_{i}(t)}{N}\right)
\end{aligned}
$$

where $A_{1}$ is a constant to be determined, $\beta$ is the larger root of $\tau$ in the quadratic equation given by (A4), and $\phi(1)$ is obtained by setting $\tau=1$ into (A5). On the right-hand side of (18), the first term (which is negative since $A_{1}$ is negative) is the private value of the option to install one more incremental unit of capital, while the second term is the private value of the last incremental unit of installed capital. Two optimal conditions must be satisfied at $k_{i}(t)=k_{i}(t) *$ (Bertola and Caballero, 1994; Pindyck, 1988). First, the private marginal gain from increasing the capital stock must equal its marginal costs at the instant of investing, i.e.

$$
v_{1}(\cdot)=(1-h) P_{K}
$$

This is the value-matching condition. Second, condition (19) must be satisfied at the states both just before and just after the investment, thus yielding

$$
\frac{\partial v_{1}(\cdot)}{\partial Z(t)}=0 .
$$

This is called the smooth-pasting condition.

Denote $k_{s 1}(\cdot, h, t)$ (the first subscript 's' denotes the case where the investment costs are sunk) as the $k_{i}(t) *$ chosen by firm $i$ when investment is irreversible. This $k_{s 1}(\cdot, h, t)$ is solved by the following procedures. First, substituting the equilibrium condition $k_{j}(t)=k_{s 1}(\cdot, h, t)(j=1, \ldots, N)$ into both conditions (19) and (20). Second, multiplying (20) by $Z(t) /[(1-f) \beta]$, and then adding the result into (19). Finally, using the value of $\phi(1)$ defined in (A5). As a result, we obtain

$$
k_{s 1}(\cdot, h, t)=m_{1} k_{f 1}(\cdot, h, t),
$$

where $m_{1}=[\alpha / 1+\alpha]^{f(1-(1-e) \lambda / e)}(<1),-\alpha$ is the smaller root of $\tau$ in the quadratic equation given by (A4), and $k_{f 1}(\cdot, h, t)$ is given by (12). Proposition 2 will then follow.

Proposition 2: The wedge between the desired capital stock with irreversible investment, $k_{s 1}(\cdot, h, t)$, and the choice of capital stock with costlessly reversible investments, $k_{f 1}(\cdot, h, t)$, will be expanded (i.e. the multiple $m_{1}$ will be lower) in the following cases: (i) uncertainty is greater ( $\sigma$ is higher); (ii) technology shifts at a lower pace of growth ( $\eta$ is smaller); (iii) a catastrophic event is less likely to occur ( $\mu$ is lower); and (iv) the external effect of capital is higher ( $\lambda$ is larger).

Proof. See Appendix B.

The intuition behind Proposition 2 is as follows. As is well known in real options literature, the combination of irreversibility and uncertainty will induce an individual firm to be more prudent, i.e. the maxim 'better safe than sorry' applies. Given that a firm invests in R\&D capital when the payoff is uncertain, the implication of this maxim is that the firm's optimal stock of R\&D capital will be lower as compared to the case when either there is no uncertainty or when is complete reversibility. As either uncertainty becomes greater or technology progresses at a lower rate, the 'desired' capital stock for costlessly reversible investments will remain unchanged while that for irreversible ones will be reduced. Accordingly, this maxim will become more important. As either a catastrophic event becomes less likely to occur, or the externality is stronger, the 'desired' capital stock for costlessly reversible investments will be raised by a proportion more than it will be for irreversible ones. Accordingly, this maxim will also become more important.

Consider the optimal conditions when disinvestment occurs. The value-matching and smooth-pasting conditions which must be satisfied at $k_{i}(t)=k_{i}(t) *$ are respectively given by

$$
\begin{gathered}
v_{1}(\cdot)=(1-\mu) \theta P_{K}, \\
\frac{\partial v_{1}(\cdot)}{\partial Z(t)}=0 .
\end{gathered}
$$

Denote $k_{d 1}(\cdot, u, t)$ (the first subscript ' $\mathrm{d}$ ' denotes the case for disinvestment) as the $k_{i}(\cdot, t) *$ chosen by firm $i$ when investment is irreversible. Solving conditions (22) and (23) simultaneously, and then imposing the equilibrium condition $k_{j}(t)^{*}=k_{d 1}(\cdot, u, t)(j=1, \ldots, N)$ yields

$$
k_{d 1}(\cdot, u, t)=m_{2} k_{s 1}(\cdot, u, t),
$$

where $m_{2}=\theta^{-1 /(f(1-(1-e) \lambda / e))}(>1)$. The equality given by (24) indicates that the ratio of the capital stock that triggers disinvestment over that which triggers investment, i.e. the factor $m_{2}$, will be expanded as the size of capital irreversibility, i.e. $1-\theta$, becomes larger. Following Pindyck (1988), this implies that disinvestment will be less likely to occur as capital investment exhibits a higher irreversibility.

Now consider the optimal investment and disinvestment decisions for a social planner. In the long-run, the social planner will internalize the external effect when choosing an optimal path of $k_{i}(t)$ to maximize the expected discounted social flow profit, net of the investment costs or plus the proceeds from selling 
capital. Suppose that $V_{2}\left(k_{i}(t), Z(t)\right)$ denotes the Bellman value function of the social planner, which is given by

$$
\begin{aligned}
V_{2}(\cdot) & =\max _{\left\{k_{i}(\tau)\right\}} E_{t} \int_{t}^{\infty} e^{-\rho(\tau-t)} \times\left[\pi_{i}^{2}\left(k_{i}(\tau), Z(\tau)\right) \mathrm{d} \tau\right. \\
& \left.-1_{\left[\mathrm{d} k_{i}(\tau)>0\right]} P_{K} \mathrm{~d} k_{i}(\tau)+1_{\left[\mathrm{d} k_{i}(\tau)<0\right]} P_{K} \mathrm{~d} k_{i}(\tau)\right],
\end{aligned}
$$

where $\pi_{i}^{2}(\cdot)$ is given by (10). The maximization problem faced by the social planner has two state variables, $Z(t)$ and $k_{i}(t) ; Z(t)$ is exogenously given, while $k_{i}(t)$ is subject to control. Let us still define $k_{i}(t) *$ and $k_{i}(t) *$ as the respective upper and lower barriers of the capital stock. When $k_{i}(t)^{*}>k_{i}(t)>k_{i}(t)_{*}$, the social marginal gain from increasing the capital stock, $v_{2}(\cdot)=\partial V_{2}(\cdot) / \partial k_{i}(t)$, is given by (see Appendix A)

$$
\begin{aligned}
& v_{2}(\cdot)=A_{2}\left[Z(t)^{1-f} k_{i}(t)^{f((1-e) \lambda / e-1)}\right]^{\beta} \\
& +\frac{d_{0}(1-e) f(1-\gamma+\lambda)}{\phi(1) e} Z(t)^{1-f} k_{i}(t)^{f((1-e) \lambda / e-1)},
\end{aligned}
$$

where $A_{2}$ is a constant to be determined. The valuematching and smooth-pasting conditions applied to $v_{2}(\cdot)$ are respectively given by

$$
v_{2}(\cdot)=P_{K}
$$

and

$$
\frac{\partial v_{2}(\cdot)}{\partial Z(t)}=0
$$

These two equations must be satisfied at $k_{i}(t)=k_{i}(t) *$.

Suppose that $k_{s 2}(\cdot, t)$ denotes the 'desired' capital stock $k_{i}(t) *$ chosen by a social planner when investment is irreversible. This $k_{s 2}(\cdot, t)$ is solved by the following procedures. First, evaluating the left-hand side of both conditions (27) and (28) at $k_{i}(t)=k_{s 2}(\cdot, t)$. Second, multiplying $(28)$ by $Z(t) /[-(1-f) \beta]$, and then adding the result into (27). Finally, using the value of $\phi$ (1) defined in (A5). As a result, we obtain

$$
\begin{aligned}
& \frac{d_{0}(1-e) f(1-\gamma+\lambda) \alpha}{e \rho(\alpha+1)} \\
& \quad \times Z(t)^{1-f_{k_{s 2}}(\cdot, t)^{f(1-(1-e) \lambda / e)}=P_{K} .}
\end{aligned}
$$

Solving for $k_{s 2}(\cdot, t)$ in (29) yields

$$
k_{s 2}(\cdot, t)=m_{1} k_{f 2}(\cdot, t)
$$

where $m_{1}$ is given by $(21)$ and $k_{f 2}(\cdot, t)$ is given by (14).

In the absence of any regulations, the social marginal gain from increasing the capital stock, the left-hand side of (27), will outweigh its private marginal gain, the left-hand side of (19). Consequently, a social planner will choose a higher 'desired' capital stock than that chosen by an individual firm. Both an investment tax credit given to firms and a tax on disinvestment will be optimal if they cause both the decentralized and the command economy to have identical upper and lower barriers of capital stocks. ${ }^{5}$ Proposition 3 derives the optimal rate of investment tax credits.

Proposition 3: Denote the optimal rate of investment tax credits for irreversible investments as $h_{s}^{*}$, then

$$
h_{s}^{*}=\frac{\lambda}{(1-\gamma+\lambda)}\left(1-\frac{1}{N}\right)
$$

Proof: $h_{s}^{*}$ is the $h$ that satisfies

$$
k_{s 1}(\cdot, h, t)=k_{s 2}(\cdot, t) .
$$

By replacing $k_{s 1}(\cdot, h, t)$ given by $(21)$ with $k_{s 2}(\cdot, t)$ given by (30) yields $h_{s}^{*}$ as that shown by (31).

Comparing $h_{f}^{*}$ given by (15) with $h_{s}^{*}$ given by (31) yields Corollary 1.

Corollary 1: An equal rate of tax credits should be given to both costlessly reversible investments and irreversible ones.

The intuition behind Corollary 1 is as follows. Evaluating (21) at $h=0$, and then dividing each side of (30) by its counterpart of (21) yields $k_{f 2}(\cdot, t) / k_{f 1}(\cdot, 0, t)=k_{s 2}(\cdot, t) / k_{s 1}(\cdot, 0, t)$. In other words, in the absence of any regulations, the ratio between the social and private optimal stocks of R\&D capital when investment exhibits complete reversibility is equal to its counterpart when investment exhibits irreversibility. Consequently, irreversibility is irrelevant to the optimal rate of investment tax credits.

Consider the optimal conditions for a social planner who sells installed capital. The value-matching and smooth-pasting conditions required to be satisfied at $k_{i}(t)=k_{i}(t)^{*}$ are respectively given by

$$
\begin{aligned}
& v_{2}(\cdot)=\theta P_{K}, \\
& \frac{\partial v_{2}(\cdot)}{\partial \mathrm{Z}(\mathrm{t})}=0 .
\end{aligned}
$$

Denote $k_{d 2}(\cdot, t)$ as the $k_{i}(t) *$ chosen by the social planner when investment is irreversible. Solving conditions (33) and (34) simultaneously, and then imposing $k_{i}(t)^{*}=k_{d 2}(\cdot, t)$ yields

$$
k_{d 2}(\cdot, t)=m_{2} k_{s 2}(\cdot, t) .
$$

where $m_{2}$ is given by (24).

In the absence of any regulations, an individual firm will sell installed capital earlier than socially desirable, as suggested by $k_{d 2}(\cdot, t)>k_{d 1}(\cdot, 0, t)$. Consequently, a tax should be imposed, and its optimal rate is given by Proposition 4. 
Proposition 4: Denote the tax rate that should be imposed on firms selling capital that exhibits irreversibility as $u^{*}$, then

$$
u^{*}=\frac{\lambda}{(1-\gamma+\lambda)}\left(1-\frac{1}{N}\right)
$$

Proof: $u^{*}$ is the $u$ that satisfies $k_{d 1}(\cdot, u, t)=k_{d 2}(\cdot, t)$. Substituting $k_{d 1}(\cdot, u, t)$ given by $(24)$ and $k_{d 2}(\cdot, t)$ given by (35) into this equality yields $u^{*}$ as that shown by (36).

Comparing Proposition 3 with Proposition 4 yields Corollary 2.

Corollary 2: The rate of taxation that should be imposed on disinvestment, $u^{*}$, is equal to the rate of tax credits required to subsidize investment. This common rate will be higher as either $\lambda /(1-\gamma)$ is higher or $N$ is larger.

The intuition behind Corollary 2 is as follows. Evaluating (24) at $u=0$, and then dividing each side of (35) by its counterpart of (24) yields $k_{s 2}(\cdot, t) / k_{s 1}(\cdot, 0, t)=k_{d 2}(\cdot, t) / k_{d 1}(\cdot, 0, t)$. In other words, in the absence of any regulations, the ratio between the social and private lower barriers of R\&D capital, $k_{s 2}(\cdot, t) / k_{s 1}(\cdot, 0, t)$, coincides with the ratio between the social and private upper barriers of R\&D capital, $k_{d 2}(\cdot, t) / k_{d 1}(\cdot, 0, t)$. Consequently, the optimal subsidy rate on investment will be equal to the optimal penalty rate on disinvestment. This common rate will be higher as either the ratio between the external and the internal effect of capital, $\lambda /(1-\gamma)$, becomes higher, or the industry is composed of more firms; this is because in both cases, the inefficiencies caused by ignoring externality become more significant.

\section{Numerical examples}

We establish a set of central values for the parameters and then investigate a wide variation around this. The benchmark parameter values are as follows: the (riskadjusted) discount rate $\rho=5 \%$ per year, the price of capital $P_{K}=2$, the wage rate $w=1$, demand elasticity $\varepsilon=5$, the size of the internal effect $1-\gamma=0.3$, the size of the external effect $\lambda=0.1$, the number of firms $=100$, the technology-shift factor $Z(t)=500$, the hazard rate $\mu=10 \%$ per year, the drift parameter $\eta=0$, the volatility parameter $\sigma=20 \%$ per year, and the size of irreversibility $1-\theta=0.1 .^{6}$ Given these central case of parameter values, Table 1 shows that factor $m_{1}=0.46$, factor $m_{2}=1.47$, and that the rate of tax credits for costlessly reversible investments $\left(h_{f}^{*}\right)$, for irreversible investments $\left(h_{s}^{*}\right)$, and the penalty rate on disinvestment $\left(u^{*}\right)$ should be equal to $24.75 \%$.
Table 1 also reports the effects of a rise in $\sigma$ in a region over $(0,40 \%), \mu$ in a region over $(5 \%, 15 \%), \eta$ in a region over $(-1 \%, 1 \%), \lambda$ in a region over $(0,0.15)$, and $h$ in a region over $(10 \%, 50 \%)$ on $k_{f 1}(\cdot)$, $k_{f 2}(\cdot), k_{s 1}(\cdot), k_{s 2}(\cdot), m_{1}$, and $m_{2}$. The results of Table 1 (see also Figures 1-4) show that no matter whether the economy is decentralized or centralized, investment is more likely to occur, that is, the 'desired' capital stock when investment is irreversible is larger, as (i) uncertainty $(\sigma)$ is smaller; (ii) technology shifts at a higher pace of growth ( $\eta$ is larger); (iii) a catastrophic event is less likely to happen ( $\mu$ is lower); and (iv) the external effect of capital is more significant $(\lambda$ is

Table 1. Capital stock, option value multiple and optimal investment tax credit rate. Central Case: $\rho=0.05, P_{K}=2$, $w=1, \quad \varepsilon=5, \quad 1-\gamma=0.3, \quad \lambda=0.1, \quad N=100, \quad Z(t)=500$, $\mu=0.1, \quad \eta=0.0, \quad 1-\theta=0.1 ; \quad m_{1}=0.46, \quad m_{2}=1.47$, $h_{f}^{*}=h_{s}^{*}=u^{*}=24.75 \%$

\begin{tabular}{|c|c|c|c|c|c|}
\hline \multirow{7}{*}{$\begin{array}{l}k_{f 1}(\cdot, 0, t) \\
k_{f 2}(\cdot, t) \\
k_{s 1}(\cdot, 0, t) \\
k_{s 2}(\cdot, t) \\
m_{1}\end{array}$} & \multicolumn{4}{|c|}{ Variation in $\sigma$} & \multirow{3}{*}{$\begin{array}{l}40 \% \\
2.43\end{array}$} \\
\hline & \multirow{2}{*}{$\begin{array}{l}0 \\
2.43\end{array}$} & \multirow{2}{*}{$\begin{array}{l}10 \% \\
2.43\end{array}$} & \multirow{2}{*}{$\begin{array}{l}20 \% \\
2.43\end{array}$} & \multirow{2}{*}{$\begin{array}{l}30 \% \\
2.43\end{array}$} & \\
\hline & & & & & \\
\hline & 6.89 & 6.89 & 6.89 & 6.89 & 6.89 \\
\hline & 2.43 & 1.66 & 1.11 & 0.72 & 0.46 \\
\hline & 6.89 & 4.71 & 3.14 & 2.05 & 1.32 \\
\hline & 1.00 & 0.68 & 0.46 & 0.30 & 0.19 \\
\hline & \multicolumn{4}{|c|}{ Variation in $\eta$} & \\
\hline & $-1 \%$ & $-0.5 \%$ & 0 & $0.5 \%$ & $1 \%$ \\
\hline$k_{f 1}(\cdot, 0, t)$ & 2.43 & 2.43 & 2.43 & 2.43 & 2.43 \\
\hline$k_{f 2}(\cdot, t)$ & 6.89 & 6.89 & 6.89 & 6.89 & 6.89 \\
\hline$k_{s 1}(\cdot, 0, t)$ & 1.04 & 1.07 & 1.11 & 1.14 & 1.18 \\
\hline$k_{s 2}(\cdot, t)$ & 2.94 & 3.04 & 3.14 & 3.24 & 3.34 \\
\hline \multirow[t]{3}{*}{$m_{1}$} & 0.43 & 0.44 & 0.46 & 0.47 & 0.49 \\
\hline & \multicolumn{4}{|c|}{ Variation in $\mu$} & \\
\hline & $5 \%$ & $7.5 \%$ & $10 \%$ & $12.5 \%$ & $15 \%$ \\
\hline$k_{f 1}(\cdot, 0, t)$ & 10.74 & 4.74 & 2.43 & 1.38 & 0.85 \\
\hline$k_{f 2}(\cdot, t)$ & 30.45 & 13.44 & 6.89 & 3.91 & 2.40 \\
\hline$k_{s 1}(\cdot, 0, t)$ & 4.05 & 1.99 & 1.11 & 0.67 & 0.43 \\
\hline$k_{s 2}(\cdot, t)$ & 11.49 & 5.66 & 3.14 & 1.90 & 1.22 \\
\hline \multirow[t]{3}{*}{$m_{1}$} & 0.38 & 0.42 & 0.46 & 0.49 & 0.51 \\
\hline & \multicolumn{4}{|c|}{ Variation in $\lambda$} & \\
\hline & 0 & 0.05 & 0.1 & 0.125 & 0.15 \\
\hline$k_{f 1}(\cdot, 0, t)$ & 1.69 & 1.94 & 2.43 & 2.91 & 3.82 \\
\hline$k_{f 2}(\cdot, t)$ & 1.69 & 2.94 & 6.89 & 13.23 & 34.54 \\
\hline$k_{s 1}(\cdot, 0, t)$ & 1.06 & 1.07 & 1.11 & 1.13 & 1.18 \\
\hline$k_{s 2}(\cdot, t)$ & 1.06 & 1.63 & 3.14 & 5.15 & 10.64 \\
\hline$m_{1}$ & 0.62 & 0.56 & 0.46 & 0.39 & 0.31 \\
\hline$m_{2}$ & 1.26 & 1.34 & 1.47 & 1.59 & 1.79 \\
\hline \multirow[t]{3}{*}{$h_{f}^{*}=h_{s}^{*}=u^{*}(\%)$} & 0.00 & 14.14 & 24.75 & 29.12 & 33.00 \\
\hline & \multicolumn{4}{|c|}{ Variation in $h$} & \\
\hline & $10 \%$ & $20 \%$ & $30 \%$ & $40 \%$ & $50 \%$ \\
\hline$k_{f 1}(\cdot, h, t)$ & 3.57 & 5.50 & 8.98 & 15.80 & 30.83 \\
\hline$k_{f 2}(\cdot, t)$ & 6.89 & 6.89 & 6.89 & 6.89 & 6.89 \\
\hline$k_{s 1}(\cdot, h, t)$ & 1.63 & 2.51 & 4.09 & 7.20 & 14.06 \\
\hline$k_{s 2}(\cdot, t)$ & 3.14 & 3.14 & 3.14 & 3.14 & 3.14 \\
\hline
\end{tabular}


higher). Table 1 (see Figure 5) also shows that investment tax credits are effective regardless of whether investment is irreversible or not because a more generous tax credit policy raises both the choice of capital stock when investment is costlessly reversible and also the 'desired' capital stock when investment is irreversible.

Table 1 also yields results that conform to those in the last section (see also Figures 1-5). First, in the absence of any regulations, the ratio between the desired capital stock with irreversible investments, $k_{s 1}(\cdot, 0, t)$, and the choice of capital stock with costlessly reversible investments, $k_{f 1}(\cdot, 0, t)$, will be lower (i.e. $m_{1}$ will be lower) in the following cases: (i) uncertainty is greater ( $\sigma$ is higher); (ii) technology progresses at a lower pace of growth ( $\eta$ is smaller); (iii) a catastrophic event is less likely to occur ( $\mu$ is lower); and (iv) the external effect of capital is stronger ( $\lambda$ is higher). This confirms the result of Proposition 2. Second, $\quad k_{f 2}(\cdot, t) / k_{f 1}(\cdot, 0, t)=k_{s 2}(\cdot, t) / k_{s 1}(\cdot, 0, t)$. In other words, in the absence of any regulations, the following two ratios will be equal: (i) the ratio between the social and private choices of capital stocks when investment is costlessly reversible; and (ii) the ratio between the social and private 'desired' capital stocks when investment is irreversible. Finally, the common ratio stated above leads to a common value of the optimal rate of investment tax credits for costlessly reversible investments and that for irreversible investments, as suggested by Corollary 1 . This common rate is irrelevant to variations in the volatility parameter $\sigma$, the drift parameter $\eta$, and the hazard rate $\mu$. In contrast, this common rate will be higher as the size of externality $\lambda$ becomes more significant. For example, given all parameter values of the benchmark case, except that $\lambda$ is raised from its central value 0.1 to 0.15 ,

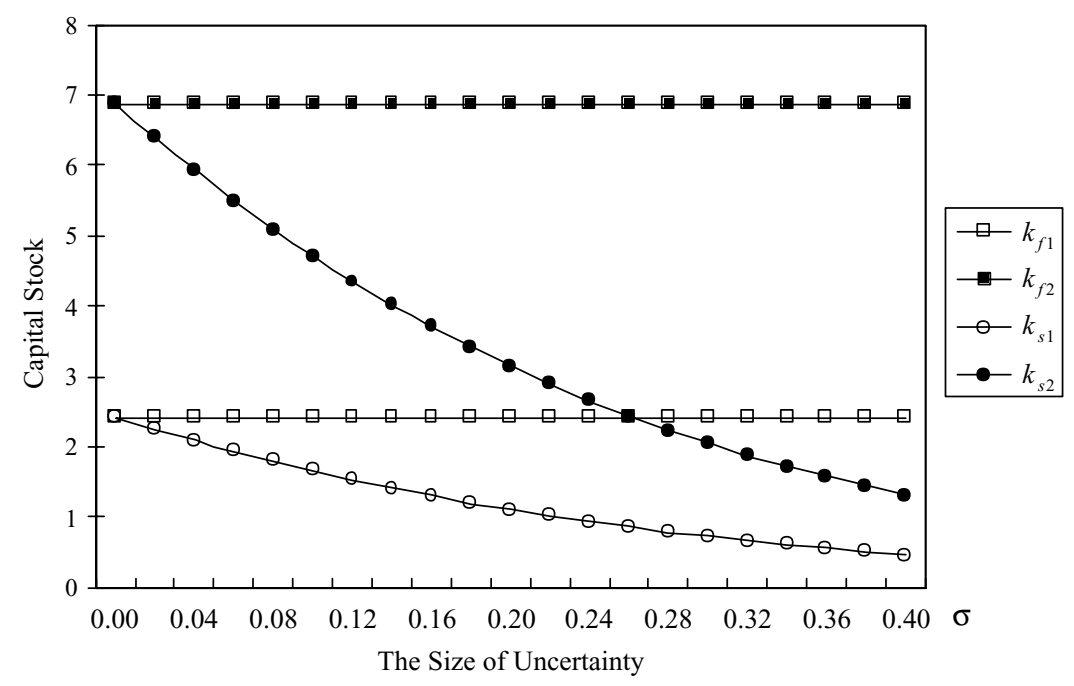

Figure 1. The effect of a change in the size of uncertainty.

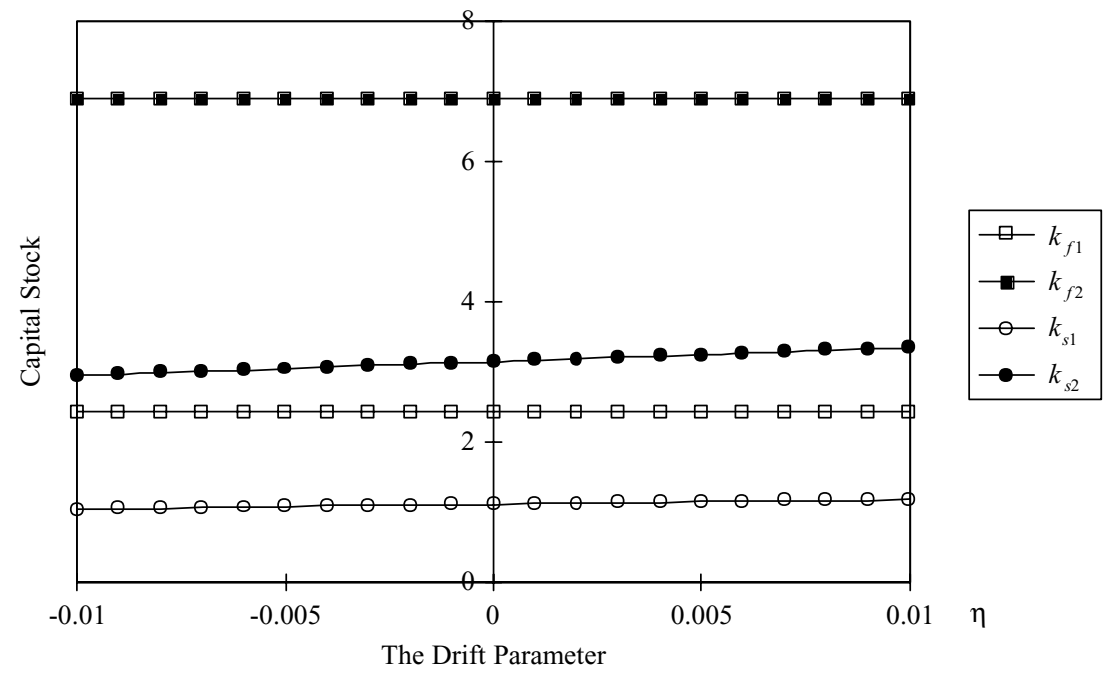

Figure 2. The effect of a change in the drift parameter. 


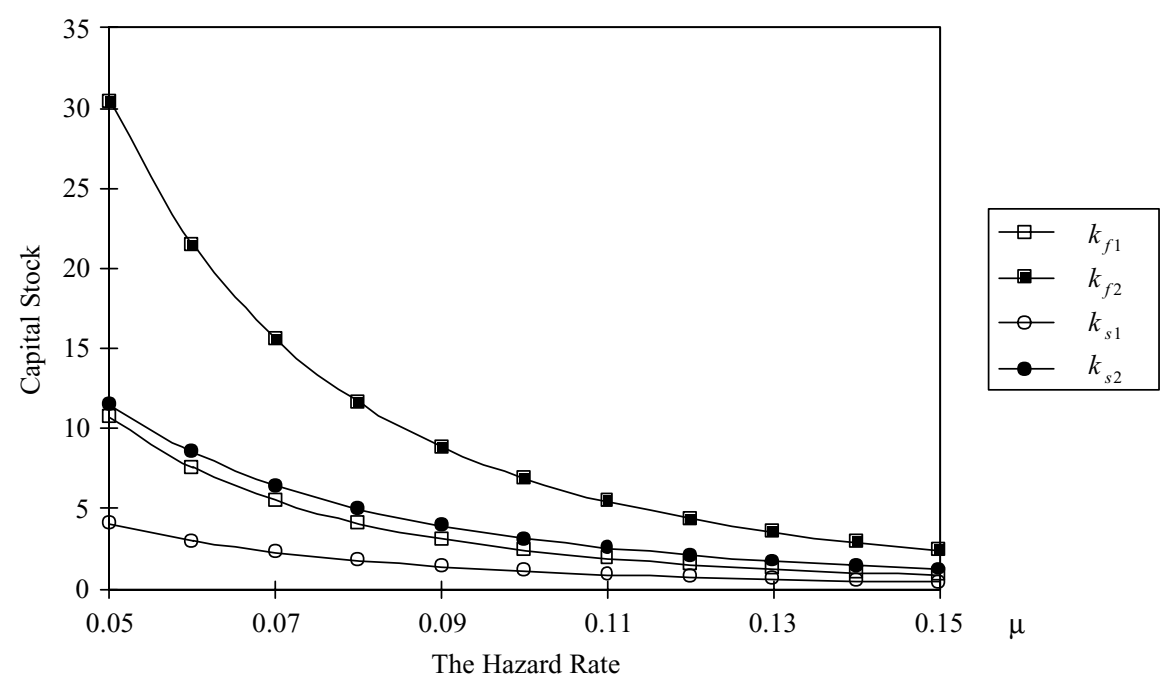

Figure 3. The effect of a change in the hazard rate.

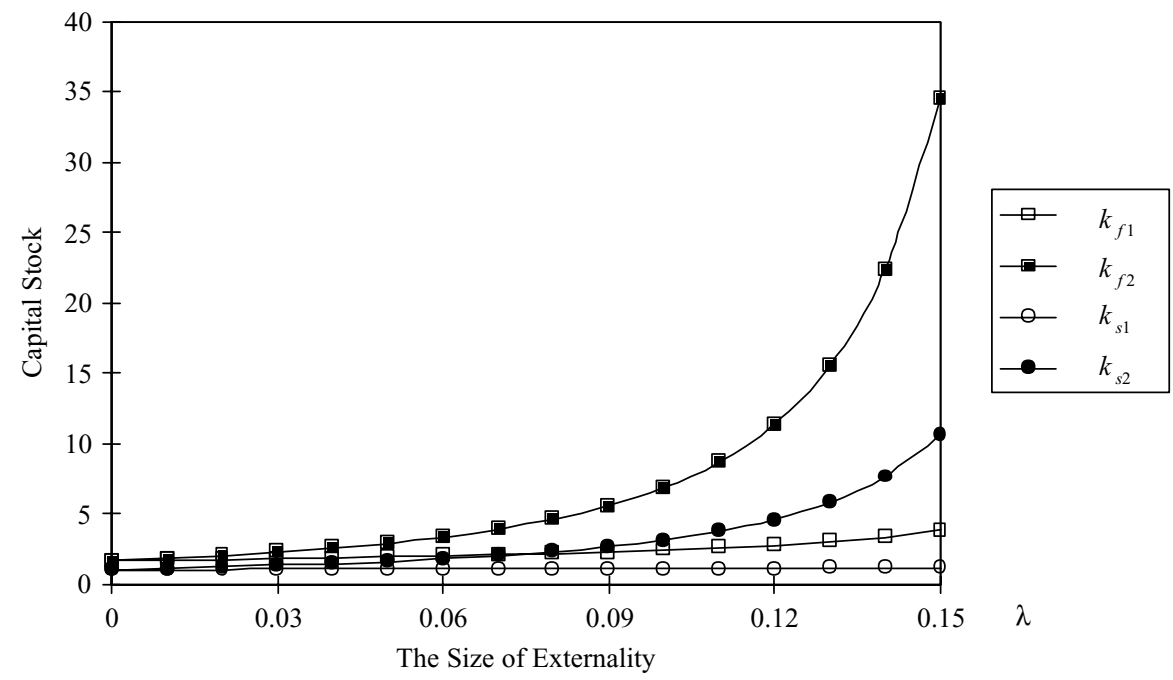

Figure 4. The effect of a change in the size of externality.

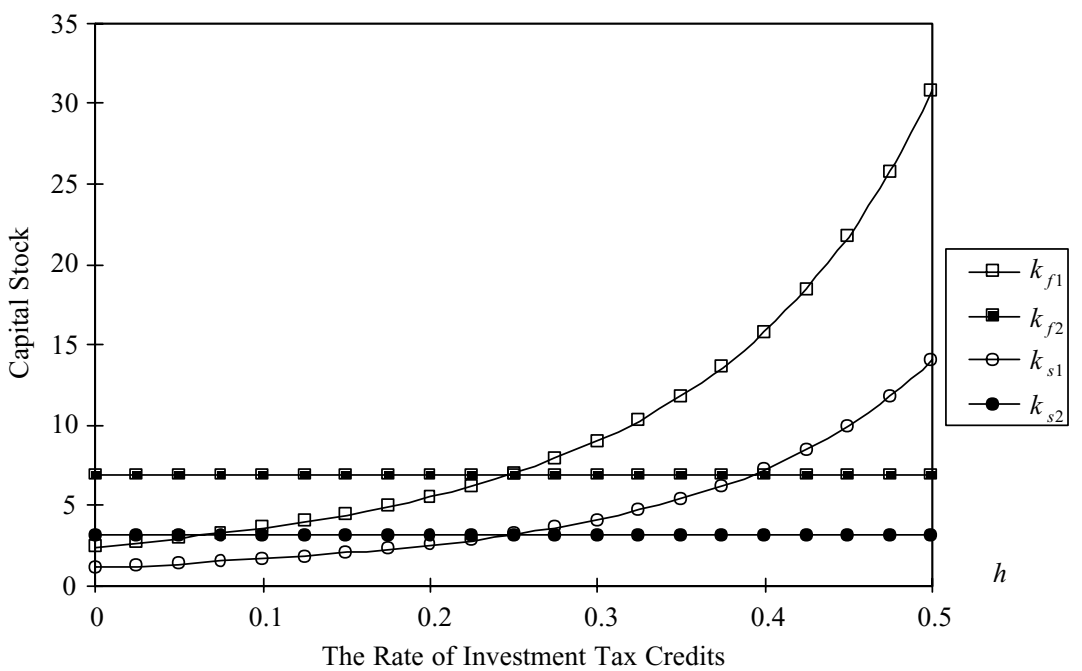

Figure 5. The effect of a change in the rate of investment tax credits. 
then this common rate will be raised from $24.75 \%$ to $33 \%$. This confirms the result of Corollary 2 .

\section{Conclusion}

This article assumes that a firm facing technological uncertainty must decide whether to purchase R\&D capital at each instant. R\&D capital exhibits both irreversibility and externality through the learning-bydoing effect. The combination of irreversibility and uncertainty drives agents to be more prudent, i.e. the maxim 'better safe than sorry' applies. This maxim is more important as uncertainty is greater, technology progresses at a lower pace, the externality is stronger, or a catastrophic event is less likely to occur. A firm ignoring the externality will both invest later and disinvest earlier than a social planner who internalizes the externality. An equal rate of investment tax credits should be given to both costlessly reversible investments and irreversible ones, and the same rate of taxation should be imposed on disinvestment.

Corollary 2 of this article indicates that asset characteristics such as irreversibility and uncertainty are irrelevant to the optimal tax incentives. It can be shown that asset durability is also unrelated to the optimal tax incentives if we allow capital to be depreciating at a constant exponential rate. Nevertheless, it is common for a government to give more generous tax credits to either (i) short-lived assets such as equipment than long-lived assets such as structures (Gravelle, 1994) or (ii) high-technology industries that use capital assets with either a higher expected growth pace of technology or greater degree of technological uncertainty. Accordingly, it deserves investigating whether Corollary 2 of this article still holds if we relax several main assumptions which include (i) demand is constant elastic; (ii) production technology is of a Cobb-Douglas type; (iii) production externality arises from the 'learning-by-doing' effect.

Future research may also relax several other assumptions of this article. First, firms may be better informed on their R\&D technology (e.g. Gaudet, Lasserre and Long, 1998). Second, R\&D decisions may be characterized in a sequence (e.g. Bar-Ilan and Strange, 1998; Grenadier and Weiss, 1997). Third, capital investment may take time to build (e.g. Majd and Pindyck, 1987; Bar-Ilan and Strange, 1998). Finally, strategic interactions between firms in making R\&D investments may be important (Lambrecht, 2000; Weeds, 1999b)

\section{Acknowledgements}

We thank an anonymous referee for comments on this article. Financial support under Grant NSC-89-2416-
H-147-002 from the National Science Council, Executive Yuan, R.O.C., is gratefully acknowledged.

\section{Appendix A: Derivation of $v_{1}(\cdot)$ and $v_{2}(\cdot)$}

We will solve $v_{1}(\cdot)$ given by (18) first, and later for $v_{2}(\cdot)$ given by (26). Suppose that $k_{i}(t)^{*}>k_{i}(t)>k_{i}(t) *$. Treating $V_{1}(\cdot)$ as an asset value, using (3) and applying Itô's lemma yields its expected capital gain as

$$
E_{t} \frac{\mathrm{d} V_{1}(\cdot)}{\mathrm{d} t}=\frac{1}{2} \sigma^{2} Z(t)^{2} \frac{\partial^{2} V_{1}(\cdot)}{\partial Z(t)^{2}}+\eta Z(t) \frac{\partial V_{1}(\cdot)}{\partial Z(t)} .
$$

This expected capital gain plus the dividend $d_{0}\left[Z(t) k_{i}(t)\right]^{(1-f)} k_{a}(t)^{(1-e) f \lambda / e}, \quad \pi_{i}^{1}(\cdot)$ given by (9), should be equal to the normal return $(\rho+\mu) V_{1}(\cdot)$ to prevent any arbitrage profits from arising. This yields the differential equation

$$
\begin{aligned}
& \frac{1}{2} \sigma^{2} Z(t)^{2} \frac{\partial^{2} V_{1}(\cdot)}{\partial Z(t)^{2}}+\eta Z(t) \frac{\partial V_{1}(\cdot)}{\partial Z(t)} \\
& -(\rho+\mu) V_{1}(\cdot)+d_{0}\left[Z(t) k_{i}(t)\right]^{1-f} k_{a}(t)^{(1-e) f \lambda / e}=0 .
\end{aligned}
$$

Let $\partial V_{1}(\cdot) / \partial k_{i}(t)=v_{i}(\cdot)$. Differentiating (A2) term by term with respect to $k_{i}(t)$ yields

$$
\begin{aligned}
& \frac{1}{2} \sigma^{2} Z(t)^{2} \frac{\partial^{2} v_{1}(\cdot)}{\partial Z(t)^{2}}+\eta Z(t) \\
&+\frac{d_{0}(1-e) f}{\partial Z(t)} Z(t)^{(1-f)} k_{i}(t)^{-f} k_{a}(t)^{(1-e) f \lambda / e-1} \\
& e \\
& \times\left[\theta k_{a}(t)+\frac{\lambda k_{i}(t)}{N}\right]=0 .
\end{aligned}
$$

By Bertola and Caballero (1994, Appendix), the term $\left[Z(t)^{(1-f)} k_{i}(t)^{(-f)} k_{a}(t)^{(1-e) f \lambda / e-1}\left(\theta k_{a}(t)+\lambda k_{i}(t) / N\right)\right]^{\tau}$ solves the homogeneous part of the quadratic equation (A3). Substituting this into (A3) yields the quadratic equation

$$
\begin{aligned}
& \phi(\tau)=-\frac{1}{2} \sigma^{2}(1-f) \tau {[(1-f) \tau-1] } \\
&-(1-f) \eta \tau+(\rho+\mu)=0 .
\end{aligned}
$$

Denote $\beta$ and $-\alpha$ respectively as the larger and smaller roots in the quadratic equation given by (A4). Following Dixit (1991), equation (A4) can be rewritten as

$$
\begin{aligned}
\phi(\tau) & =\frac{1}{2}(1-f)^{2} \sigma^{2}(\alpha+\tau)(\beta-\tau) \\
& =\frac{(\rho+\mu)(\alpha+\tau)(\beta-\tau)}{\alpha \beta},
\end{aligned}
$$

where $\phi(\tau)>0$ if $-\alpha<\tau<\beta$. Figure 6 depicts $\phi(\tau)$ as a function of $\tau$. 


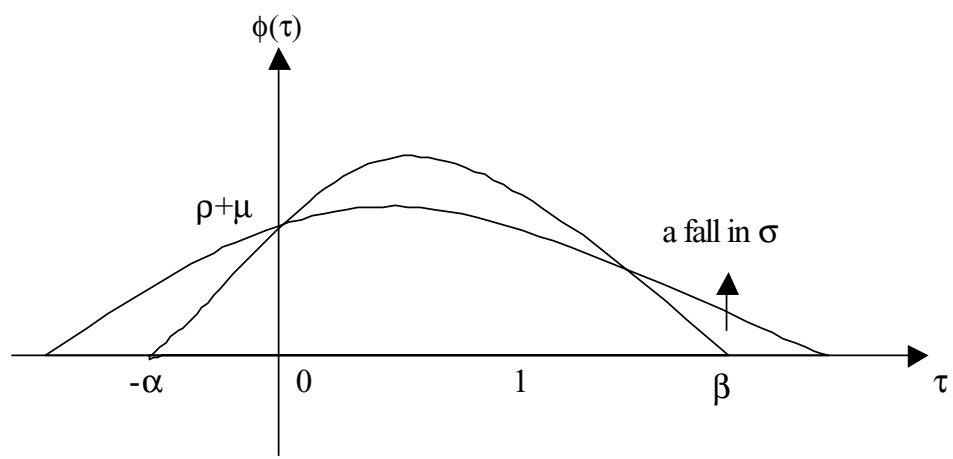

Figure 6. $\phi(\tau)$ vs. $\tau$.

One particular solution from the non-homogeneous part of equation (A3) is given by

$$
\begin{aligned}
v_{1 P}(\cdot)= & \frac{d_{0}(1-e) f}{\phi(1) e} Z(t)^{(1-f)} k_{i}(t)^{(-f)} k_{a}(t)^{(1-e) f \lambda / e-1} \\
& \times\left(\theta k_{a}(t)+\frac{\lambda k_{i}(t)}{N}\right)
\end{aligned}
$$

Since the value function $V_{1}(\cdot)$ must approach zero as $Z(t)$ approaches zero, only the positive root of equation (A4) should be considered. The general solution of equation (A3), which is composed of solutions from both the homogeneous and nonhomogeneous parts of equation (A3), is shown by (18). Following similar procedures as above yields $v_{2}(\cdot)=\partial V_{2}(\cdot) / \partial k_{i}$ as shown by (26).

\section{Appendix B: Proof of Proposition 2}

Let $E=\alpha /(1+\alpha)<1$ and $G=1 /(f(1-(1-e) \lambda / e))>0$, then $m_{1}=E^{G}$. Differentiating $m_{1}$ with respect to $\eta, \sigma, \mu$, and $\lambda$ yields the following results.

$$
\begin{aligned}
\frac{\partial m_{1}}{\partial \sigma} & =\frac{m_{1} G}{\alpha(1+\alpha)} \frac{\partial \alpha}{\partial \sigma}<0, \\
\text { where } \frac{\partial \alpha}{\partial \sigma} & =\frac{\partial \phi(-\alpha) / \partial \sigma}{\partial \phi(-\alpha) / \partial \tau}<0, \quad \text { since } \frac{\partial \phi(-\alpha)}{\partial \sigma} \\
& =-\sigma[(1-f)(-\alpha)][(1-f)(-\alpha)-1]<0,
\end{aligned}
$$

and

$$
\frac{\partial \phi(-\alpha)}{\partial \tau}>0
$$

from Figure 1;

$$
\frac{\partial m_{1}}{\partial \eta}=\frac{m_{1} G}{\alpha(1+\alpha)} \frac{\partial \alpha}{\partial \eta}>0
$$

where $\frac{\partial \alpha}{\partial \eta}=\frac{\partial \phi(-\alpha) / \partial \eta}{\partial \phi(-\alpha) / \partial \tau}>0$, since $\frac{\partial \phi(-\alpha)}{\partial \eta}$

$$
=(1-f) \alpha>0, \quad \text { and } \quad \frac{\partial \phi(-\alpha)}{\partial \tau}>0 ;
$$

$$
\frac{\partial m_{1}}{\partial \mu}=\frac{m_{1} G}{\alpha(1+\alpha)} \frac{\partial \alpha}{\partial \mu}>0
$$

where $\frac{\partial \alpha}{\partial \mu}=\frac{\partial \phi(-\alpha) / \partial \mu}{\partial \phi(-\alpha) / \partial \tau}>0$, since $\frac{\partial \phi(-\alpha)}{\partial \mu}=1$,

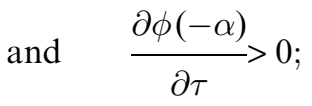

$$
\frac{\partial \mathrm{m}_{1}}{\partial \lambda}=\mathrm{m}_{1} \ln \frac{\alpha}{(1+\alpha)} \frac{\partial G}{\partial \lambda}<0
$$

since $\frac{\partial G}{\partial \lambda}=G^{2} f(1-e) / e>0$.

\section{References}

Arrow, K.J. (1962) The economic implications of learning by doing. Review of Economic Studies, 29, 155-173.

Baldursson, F.M. (1998) Irreversible investment under uncertainty in oligopoly. Journal of Economic Dynamics and Control, 22, 627-644.

Bar-Ilan, A. and Strange, W.C. (1998) A model of sequential investment. Journal of Economic Dynamics and Control, 22, 437-463.

Beath, J., Katsoulacos, Y. and Ulph, D. (1989) Strategic R\&D policy. The Economic Journal, 99, 74-83.

Bertola, G. and Caballero, R.J. (1994) Irreversibility and aggregate investment. Review of Economic Studies, 61, 223-246.

Brennan, M.J. and Schwartz, E.S. (1985) Evaluating natural resource investments. Journal of Business, 58, 135-157.

Dixit, A.K. (1989) Entry and exit decisions under uncertainty. Journal of Political Economy, 97, 620-638. 
Dixit, A.K. (1991) Irreversible investment with price ceilings. Journal of Political Economy, 99, 541-57.

Dixit, A.K. and Pindyck, R.S. (1994) Investment under Uncertainty. Princeton NJ: Princeton University Press.

Fudenberg, D., Gilbert, R., Stiglitz, J. and Tirole, J. (1983) Preemption, leapfrogging and competition in patent races. European Economic Review, 22, 3-31.

Gaudet, G., Lasserre, P. and Long, N.V. (1998) Real investment decisions under adjustment costs and asymmetric information. Journal of Economic Dynamics and Control, 23, 71-95.

Gravelle, J.G., 1994, The Economics of Taxing Capital Income. Cambridge, MIT Press.

Grenadier, S.R. and Weiss, A.M. (1997) Investment in technological innovations: an option pricing approach. Journal of Financial Economics, 44, 397-416.

Harris, C. and Vickers, J. (1985) Patent races and the persistence of monopoly. Journal of Industrial Economics, 33, 461-482.

Harrison, J.M. and Taksar, M.L. (1985) Instantaneous control of Brownian motion. Mathematical Operations Research, 8, 439-453.

Hassett, K.A. and Hubbard, R.G. (1996) Tax policy and investment, Working Paper No. 5683, National Bureau of Economic Research.

Jorgenson, D.W. (1963) Capital theory and investment behavior. American Economic Review, 53, 247-259.

Judd, K.L. (1997) The optimal tax rate for capital income is negative. NBER Working Paper, No. 6004.

Lambrecht, B. (2000) Strategy sequential investments and sleeping patents. In Brennan, M.J. and Trigeogis, L. (eds) Project flexibility, agency, and competition, Oxford University Press, 297-323.

Lint, O. and Pennings, E. (1999) The option approach to the new product development process. 3rd annual international conference on real options: theory meet practice, Wassenaar/Leiden, The Netherlands.

Lucas, R.E., Jr. (1988) On the mechanics of economic development. Journal of Monetary Economics, 22, 3-42.

Lucas, R.E., Jr. and Prescott, C. (1971) Investment under uncertainty. Econometrica, 39, 659-81.

Majd, S. and Pindyck, R.S. (1989) The learning curve and optimal production under uncertainty. RAND Journal of Economic, 20, 331-343.

Pennings, E. and Lint, O. (1997) The option value of advanced R\&D. European Journal of Operational Research, 103, 83-94.

Pindyck, R.S. (1988) Irreversible investment, capacity choice, and the value of the firm. American Economic Review, 78, 969-985.
Pindyck, R.S. (1993) Investments of uncertain cost. Journal of Financial Economics, 34, 53-76.

Roberts, K. and Weitzman, M.L. (1981) Funding criteria for research, development, and exploration projects. Econometrica, 49, 1261-1288.

Romer, P.M. (1986) Increasing returns and long-run growth. Journal of Political Economy, 99, 500-521.

Saint-Paul, G. (1992) Fiscal policy in an endogenous growth model. Quarterly Journal of Economics, 107, 1243-1259.

Schwartz, E.S. and Moon, M. (2000) Evaluating research and development investments. In M. Brennan and L. Trigeorgis (eds) Project flexibility, agency, and competition, Oxford: Oxford University Press. 85-106.

Weeds, H. (1999a) 'Reverse hysteresis': R\&D investment with stochastic innovation, 3rd annual international conference on real options: theory meet practice, Wassenaar/Leiden, The Netherlands.

Weeds, H. (1999b) Strategic delay in a real options model of $\mathrm{R} \& \mathrm{D}$ competition, 3rd annual international conference on real options: theory meet practice, Wassenaar/Leiden, The Netherlands.

Xepapadeas, A. (1999) Environmental policy and firm behavior: abatement investment and location decisions under uncertainty and irreversibility, Technical Working Paper 243. National Bureau of Economic Research, Cambridge, M.A.

\section{Notes}

1. Some studies focus solely on valuation of R\&D investment, e.g. Pennings and Lint (1997) and Lint and Pennings (1999).

2. See also Saint-Paul (1992) which emphasizes that an investment tax subsidy rather than public debt can be used to solve the externality problem.

3. Partial irreversibility may come from firm-level or industry-level specific assets, the lemons problem, or government regulation (see Dixit and Pindyck, 1994).

4. The term $e$ is required to be smaller than one to assure that the private and social marginal returns to capital are both positive. We will assume this holds in what follows.

5. See Pindyck (1988) for a proof and also Xepapadeas (1999).

6. As suggested by Dixit (1989), some capital costs arise from depreciation and are more thought of as recurrent and some costs are recoverable when disinvestment occurs. Accordingly, a ratio of $w: \rho P_{k}=10: 1$ 